Dossiê: Conferência de Medellín: 50 anos - Artigo Original ๑-은

\title{
Os leigos em Medellín: memórias e novas perspectivas
}

\author{
The laity in Medellín: memories and new perspectives
}

Cesar Kuzma*

\begin{abstract}
Resumo
O artigo que apresentamos tem a intenção de refletir sobre a vocação e missão dos leigos descrita no Documento de Medellín, dedica-se a um resgate das memórias que podemos colher, depois de 50 anos, mas, também, em atenção às novas perspectivas que o próprio documento nos traz, hoje. Medellín foi um marco importante para a história da Igreja da América Latina e voltar a esta conferência pode nos oferecer novas pistas e novos entendimentos para situações que vivemos hoje, tanto na Igreja quanto na sociedade. Assim como o Concílio Vaticano II, Medellín foi importante para uma nova posição dos leigos na Igreja e para um novo entendimento de sua ação na sociedade, com autonomia e responsabilidades próprias. Neste artigo, daremos atenção ao Concílio Vaticano II e a sua recepção criativa em Medellín. Exploraremos aspectos do capítulo que trata exclusivamente dos leigos e, na sequência, discorreremos sobre algumas questões que o tema provoca e que, depois de 50 anos, mostram-se atuais e oferecem novos caminhos.
\end{abstract}

Palavras-chaves: leigos; Medellín; Vaticano II; Igreja; América Latina.

\begin{abstract}
The article we present intends to reflect on the vocation and mission of the laity described in the Medellín Document and is dedicated to a rescue of the memories that we can collect after 50 years, but also in view of the new perspectives that the Document itself brings us today. Medellín was important for the history of the Church of Latin America and to return to this conference can offer us new clues and new understandings for situations that we live in today, both in the Church and in society. Like the Second Vatican Council, Medellín was important for a new position of the laity in the Church and for a new understanding of their action in society, with autonomy and responsibilities that are their own. In this article, we will pay special attention to the Second Vatican Council and its creative reception in Medellín. We will explore aspects of the chapter dealing exclusively with the laity, and then we will discuss some of the issues that the theme provokes us and that, after 50 years, these issues are current and offer new ways.
\end{abstract}

Keywords: laity; Medellín; Second Vatican Council; Church; Latin America.

Artigo submetido em 27 de agosto de 2018 e aprovado em 28 de agosto de 2018.

* Doutor em Teologia pela Pontifícia Universidade Católica do Rio de Janeiro - PUC-Rio. Professor de Teologia Sistemática no Departamento de Teologia da PUC-Rio - Graduação e Pós-Graduação. País de origem: Brasil. E-mail: ckuzma@puc-rio.br

Horizonte, Belo Horizonte, v. 16, n. 50, p. 632-647, maio/ago. 2018 - ISSN 2175-5841 


\section{Introdução}

No momento em que se celebram os 50 anos da Conferência de Medellín e muito se discute e se escreve sobre este tema, faz-se necessário - ainda - se perguntar sobre a atualidade de suas perspectivas para o tempo de hoje e para as novas inquietações eclesiológicas e pastorais que avançam na Igreja [Católica]; também em nível social para a América Latina. O contexto em que se vive, seguramente, já é outro, mas muitas das inquietudes percebidas e apontadas em Medellín, há 50 anos, podem iluminar o caminho atual, tendo em vista a urgência de uma nova ação de Igreja e de um diálogo maior com a sociedade, bem como a nova configuração econômico-política e social de hoje, com desequilíbrios e retrocessos em vários aspectos, sobretudo na causa do direito dos mais pobres e dos povos originários, na fragilidade das democracias vigentes, nas causas da paz e da justiça, da violência, do neocolonialismo, dentre outros.

Algo parecido se pode dizer da Igreja Católica e de suas estruturas. Mesmo tendo passado 50 anos do Concílio Vaticano II e agora 50 anos de Medellín, e com os propósitos das demais Conferências Gerais que se seguiram, a Igreja do continente - com exceções, certamente - ainda se esbarra em atitudes clericalistas, legalistas e de poder, alinhada, em alguns casos, às elites e, em certos lugares, distante da realidade concreta das pessoas. É evidente que Medellín e o seu profetismo têm algo a nos dizer hoje.

A Conferência de Medellín foi um marco para a Igreja do continente e deste evento podemos observar dois movimentos de modo bastante precisos: 1) a recepção da proposta do Concílio Vaticano II e suas colocações eclesiológicas numa linguagem própria e aplicável neste contexto histórico e cultural; 2) a intuição de um novo modo de ser Igreja na América Latina, impulsionada por uma nova teologia que estava surgindo naquele instante (da Libertação) e por um compromisso de diálogo transformador da sociedade, em vista de uma libertaçãohumanizadora. Com Medellín, a Igreja assume duas palavras-chaves do Concílio 
Vaticano II (aggiornamento e diálogo) e as amplia numa perspectiva nova, atualizando o seu modo de ser e de compreender a fé nesta realidade, por certo, desafiadora; mas também num caráter de responsabilidade perante a sociedade, marcada por opressão, pobreza, colonialismo e dependência, ditaduras militares, grande distância entre ricos e pobres, e também de uma Igreja de elite e de poder.

É por onde pretendemos abordar aqui neste trabalho, mesmo que de modo breve, a questão dos leigos e sua missão na Igreja e na sociedade, dita em Medellín, em um capítulo próprio (capítulo 10), pela atuação dos Movimentos de Leigos. No entanto, não queremos apenas reproduzir o que está no documento gerado pela Conferência Geral e que já é acessível de vários modos ao povo e às igrejas locais, mas sim entender o tempo de Medellín e puxar a intenção desta Conferência para o nosso tempo, já que ali lançou-se um olhar favorável para a Igreja e a missão que esta desempenha nesta terra, neste continente, onde o papel de leigos e leigas, homens e mulheres engajados e comprometidos com a justiça e a verdade se fazem necessários. Teremos, pois, inicialmente, um olhar desde o Concílio Vaticano II e das novidades eclesiais que surgiram e impulsionaram uma nova concepção eclesiológica, também para este continente. Depois, seguiremos para o específico da proposta de Medellín, daquilo que ela quis dizer sobre os leigos. O próximo passo é tratar algumas questões-chaves da Conferência que trazem novidade para o tema proposto, o que nos leva a um desfecho sobre os 50 anos de Medellín, que ainda nos induz e nos provoca a mudanças, a aberturas e a novos caminhos, sempre de modo libertador e humanizador, fazendo com que a missão aconteça.

\section{Medellín e a recepção da proposta do Concílio Vaticano II}

O Vaticano II ainda é um horizonte aberto e que merece ser desvendado e aplicado em muitas esferas eclesiais, teológicas e pastorais. Mesmo diante dos limites de suas próprias conclusões, algo normal pelo limite da própria teologia e das visões de mundo que se tem em cada época, ele ainda está à frente do nosso tempo e suscita novas interpelações e atualizações. Em suas conclusões, convoca a 
uma eclesiologia de base trinitária, na qual a condição de communio se faz sempre necessária. Nela, a multiplicidade de dons e carismas, que se desprende em ações contínuas e em uma ministerialidade de todos os membros, enriquece o corpo eclesial e fomenta à missão (FORTE, 2005), numa dimensão escatológica que se faz acontecer e antecipar na história. Além disso, ao nos fazer perceber os sinais dos tempos e na proposta de atualização da mensagem do Evangelho, o Vaticano II inova, conforme fazemos recordar aqui, a partir da Gaudium et Spes (GS):

Para desempenhar tal missão, a Igreja, a todo momento, tem o dever de perscrutar os sinais dos tempos e interpretá-los à luz do Evangelho, de tal modo que possa responder, de maneira adaptada a cada geração, às interrogações eternas sobre o significado da vida presente e futura e de suas relações mútuas. É necessário, por conseguinte, conhecer e entender o mundo no qual vivemos, suas esperanças, suas aspirações e sua índole dramática frequentemente. (GS 4).

Esta intenção de ação e indicação de percepção da realidade fizeram com que, após o término do Concílio, um movimento de entendimento e aplicação acontecesse, e, quanto a isso, podemos dizer que a América Latina, pela liderança de alguns bispos locais - poucos, mas proféticos - e por uma vontade de mudar e transformar o continente em linhas-mestras do Vaticano II, sobretudo pela Gaudium et Spes, o fez de modo surpreendente. Esta mudança que ocorreu na Igreja da América Latina não se deu apenas na aplicação das conclusões finais, vindas do Concílio, mas na recepção livre e criativa e na reinterpretação das mesmas conclusões diante das questões eclesiais e sociais do continente latinoamericano (COMBLIN, 2002, p. 89-90). Desta forma, ofereceu-se outro rosto à Igreja, num caminhar de uma Igreja dos pobres (SCATENA, 2008) e de uma igreja que recepciona algo peculiar e fundamental da eclesiologia do Concílio, que é a definição de Igreja como Povo de Deus.

De acordo com Comblin (2002, p. 51), esta é a principal chave hermenêutica para se ler o Concílio e suas inovações; e está é a grande novidade que possibilitou um novo acento aos leigos dentro do Vaticano II, de modo especial no capítulo II da Lumen Gentium (LG), que trata desta temática e dá base ao que se compreende 
da Igreja em sua estrutura, não podendo ser entendida apenas de modo hierárquico, mas como Povo de Deus, no qual todos os batizados fazem parte e oferecem o seu viver, as suas ações, como hóstias vivas, em razão de sua esperança (LG 10). Tem-se aí uma nova configuração eclesial, onde há diferenças em ações e responsabilidades, mas igualdade em dignidade (LG 31), pois todas as vocações formam e são chamadas ao mesmo Povo, e por ele e nele possuem um papel específico na missão da Igreja. Ninguém e/ou nenhuma vocação está acima, apenas Cristo ocupa o centro e através dele o Espírito suscita dons e carismas a todos, para a edificação e para a missão. Dentro desta concepção, os leigos assumem o múnus sacerdotal, profético e régio, participando da totalidade da missão da Igreja. Todavia, não assumem esta condição porque são leigos, mas sim porque fazem parte do Povo de Deus e é por esta nova definição que se deve avançar e entender esta vocação e as demais vocações, hoje.

Trazendo esta novidade conciliar para o ambiente da América Latina, percebe-se que a atividade dos leigos estava marcada pela Ação Católica e parte dela alicerçada em movimentos eclesiais. Porém, esta compreensão não era uma regra, já que a maioria dos fiéis leigos não possuíam uma autêntica consciência de seu ser e estar na Igreja e da relação que esta condição lhes oferecia frente aos problemas existentes na sociedade. Havia também a necessidade de uma nova identidade eclesial, descrita pela atuação de alguns movimentos [tidos como de leigos] e a noção que se tinha de sua vocação e missão, agora com a autonomia gerada pelo Concílio, que exigia uma nova formulação, a fim de atingir os resultados esperados e de encontrar na ação dos leigos uma força à altura das urgências do continente. Buscava-se, assim, uma resposta que atingisse principalmente a esfera pública e o agir temporal, bem descrito pela Lumen Gengium (LG 31b).

É o que nos leva agora a trazer um retrato da proposta de Medellín, para o laicato. 


\section{A proposta de Medellín}

O documento final da Conferência de Medellín (Med) se apresenta em 16 partes/capítulos, sendo que o capítulo $10^{\circ}$ é dedicado aos leigos, ou como dissemos acima, aos movimentos de leigos. Este se divide em quatro partes: 1) fatos; 2) critérios teológico-pastorais; 3) recomendações pastorais e 4) moções. Destas, podemos dizer que elas partem de uma constatação e nela já se alude a propostas que são específicas de Medellín, até por acentuar que uma visão mais completa da dimensão apostólica dos leigos deve ser apurada com outras partes do documento, que tratam especificamente da justiça e da paz, da família, da demografia, juventude e outras (Med 10,1), pois se faz valer a proposta do Vaticano II que insiste que o papel específico dos leigos é o mundo secular, o ambiente onde ele vive e desenvolve suas ações (LG 31b). É o que encontramos nas duas primeiras partes, já nas partes finais, busca-se recomendar as propostas delineadas para o seu cumprimento, colocando o papel das igrejas locais e do CELAM para a implementação.

A proposta de Medellín tem em vista a realidade do continente e se questiona como que a Igreja pode favorecer uma mudança e uma transformação que vise algo novo para a realidade das pessoas, principalmente para os pobres e para aqueles que sofrem opressão e violência. Desta maneira, ao tratar da missão e do apostolado dos leigos, parte-se desta perspectiva (Med 10,1) e recorda a realidade em que se vive, marcada por situações alarmantes e específicas que exigem da Igreja e de todos os fiéis uma nova postura, um enfrentamento, como já se acusou na Encíclica Populorum Progressio (1967), de Paulo VI, que segue como uma referência importante para o documento. É o que coloca os leigos, diante desta realidade complexa, num compromisso que seja, ao mesmo tempo, libertador e humanizador (Med 10,2). É a partir desta realidade que o documento procura perceber e rever a presença dos leigos na missão da Igreja no continente (Med 10,1), pois esta deve ser uma presença ativa e comprometida, numa adaptação permanente e num profícuo exercício de criatividade pastoral (Med 10,3), a fim de perceber os sinais dos tempos. 
O que se faz é exigir algo novo, já que os leigos e os movimentos por onde eles se organizavam não estavam oferecendo uma resposta suficiente. O documento, então, recorda que muitos deles tiveram ações decisivas e importantes no passado (Med 10,6), sobretudo pela Ação Católica, mas com o passar do tempo e por outras circunstâncias "fecharam-se em si mesmos, ou se aferraram indevidamente a estruturas demasiadamente rígidas, ou não souberam situar devidamente seu apostolado no contexto de um compromisso histórico libertador" (Med 10,4). Provavelmente, segue o documento, é que muitos dos movimentos de leigos não tiveram uma organização ou pedagogia apropriada para tais compromissos (Med 10,4), o que vem do resultado da fraca integração de sua vocação e das questões eclesiais, que decorrem, por sua vez, do desconhecimento que se tem da especificidade de sua missão. O mesmo se pode dizer quanto a autonomia para agir e responder enquanto Igreja no mundo, uma condição praticamente ignorada e que vem de assessores não tão bem preparados (Med 10,5); e, acrescentamos, de reflexos de uma Igreja pré-Conciliar que ainda vivia em períodos de cristandade e que numa atitude clericalista formava ou mantinha leigos passivos ou submissos à hierarquia.

Ao fundamentar teologicamente a participação dos leigos na missão da Igreja no continente latino-americano, o documento se faz valer pelo Vaticano II, basicamente pela Lumen Gentium e Gaudium et Spes, e pega dali o que é específico e que ressalta a presença dos leigos no complexo tecido da sociedade. Parte-se da definição de Igreja como Povo de Deus e afirma que "no seio do Povo de Deus, que é a Igreja, há unidade de missão e diversidade de carismas, serviços e funções, 'obra do único e mesmo Espírito', de modo que todos, a seu modo, cooperem unanimemente na obra comum (Med 10,7). Além da definição da Igreja como Povo de Deus, que, conforme pontuamos no início, é a grande chave eclesiológica do Vaticano II, destacamos a ênfase no cooperar, isto é, os leigos não colaboram como força inferior, mas cooperam, a seu modo e naquilo que é específico do seu agir. Assim, engrandecem e cumprem o seu papel no mundo, que é a definição da Lumen Gentium (LG 31b), e que reforça Medellín, ao dizer que fazem isto em vista 
"da construção da história" (Med 10,8). Melhor dizendo, no compromisso com a solidariedade humana, com a trama dos acontecimentos e fatos significativos, e para isso gozam de autonomia e responsabilidades que lhes são próprias (Med 10,9); é onde entra o valor do testemunho, num dinamismo de fé e vida (Med 10,11), através do qual os leigos fazem com que a Igreja aconteça no mundo, na tarefa humana e na história.

O documento recomenda a criação de equipes apostólicas ou de movimentos seculares ou estruturas funcionais em lugares onde se se decide o processo de libertação e humanização, com uma pedagogia adequada e atenta aos sinais dos tempos (Med 10,13). Neste trabalho, pede-se a integração de todos, bem como o apoio e suporte para aqueles que, pelas implicações sociais do Evangelho, são levados a compromissos com dolorosas consequências (Med 10,14). Há um incentivo para o compromisso dos leigos nos organismos internacionais para a promoção do progresso dos povos e para favorecer a justiça entre as nações ( Med 10,15); e, recomenda-se uma espiritualidade própria, que seja suporte para os desafios que serão enfrentados e que ajude os leigos a se entregarem a Deus, entregando-se à vida concreta das pessoas, seguindo o exemplo de Jesus (Med 10,17). Termina falando da importância da criação dos Conselhos de Leigos (Med 10,19-20).

\section{Questões de Medellín}

A seguir, oferecemos uma breve reflexão sistemática sobre questões-chaves da Conferência de Medellín, extraídas do documento, daquilo que corresponde especificamente aos leigos.

\subsection{Os leigos e o compromisso libertador-humanizador}

Medellín reforça muito o compromisso dos leigos com a transformação da realidade do continente, marcado por opressão, pobreza, questões políticas, neocolonialismo, dentre outras formas que merecem especial e urgente atenção. 
Podemos dizer que o documento dá um passo além do que foi o Vaticano II, pois indica a forma que deve ser a ação dos leigos na sociedade e em qual perspectiva podem oferecer as razões de sua esperança. De acordo com a proposta de Medellín, faz-se necessário libertar a sociedade de todas as amarras que impedem um avanço e desenvolvimento social, na intenção de incluir a todos, e isso deve ser realizado de forma humanizadora, tendo por base a Gaudium et Spes que diz que toda a ação eclesial/social deve ter o humano como referência. O documento também nos oferece um suporte de interpretação da realidade, já que a estrutura que é denunciada, sobretudo pela pobreza, acusa-nos a nossa falta social e impede todo o desenvolvimento humano. Diante deste quadro, a Igreja e, de modo bem particular, os leigos, tendo o Reino de Deus por referência, não pode estar alheia a isso, mas deve engajar-se para transformar, para mudar, para oferecer algo diferente, portanto libertador e humanizador.

\subsection{O plano escatológico no agir temporal: o valor autêntico do testemunho cristão}

O agir no mundo temporal é característico da vocação laical, mesmo não sendo exclusivo. Todos os fiéis, independente da vocação para a qual estejam chamados, estão inseridos no tecido social e, a seu modo, oferecem o seu testemunho e o seu trabalho colaborativo. No entanto, é importante frisar que, assim como fez o Vaticano II, Medellín também dá grande destaque à atuação dos leigos nos diversos campos da sociedade, nas linhas de frente do trabalho e em esferas de decisão. É onde, pela consciência motivada e iluminada pela fé, pode-se mudar a estrutura social para que ela se torne mais humanizadora e resplandeça os valores da dignidade humana e da fraternidade. No assumir da sua vocação, os leigos devem atuar na perspectiva do Reino, antecipando para o tempo presente a questão da justiça, da paz, da liberdade e do bem-comum. Valores do Reino que, escatologicamente se antecipam em ações concretas, fazendo da esperança uma força de luta e de trabalho que são garantidos pelo testemunho cristão, exercido e apresentado por leigos e leigas no vivenciar da sua vocação e missão.

Horizonte, Belo Horizonte, v. 16, n. 50, p. 632-647, maio/ago. 2018 - ISSN 2175-5841 
Não há nada mais íntimo e profundo do que o testemunho sincero de quem crê e expressa por palavras e ações concretas aquilo que crê, num dinamismo de fé e caridade que levam pessoas a se entregarem de modo profundo à causa que esperam e acreditam, dando, em alguns casos, a própria vida por alguém, por um grupo ou comunidade - no fundo, pelo Reino, por Deus. São fiéis à causa que acreditam. É quando a dimensão do martírio, tão radical no seguimento e como marca cristã se faz perceber neste continente, também entre leigos e leigas. $\mathrm{O}$ dar a vida aqui, nesta intenção, também se entende no sentido de doação total, de compromisso assumido, no fazer valer a urgência do Reino diante das complexas situações que nos cercam e impedem o desenvolvimento humano e social. $\mathrm{O}$ documento de Medellín dá grande valor ao testemunho, ao falar dos leigos, dizendo que ele se confunde com a própria vida do cristão (Med 10,11); assim, nada é guardado para si, mas tudo é compartilhado e oferecido aos outros. Aqui está o grande valor e a veracidade de toda a vocação, pois vem de uma experiência real e concreta. É onde se encontra o verdadeiro sentido do apostolado.

\subsection{Fazer com que a Igreja aconteça}

Uma das características do documento de Medellín é que com ele se tem início, de modo mais organizado, as comunidades eclesiais de base (as CEBs). As CEBs vão se tornar a grande marca do ser e fazer Igreja neste continente e nelas a ação dos leigos, homens e mulheres comprometidos com a fé e com a vida se fazem presentes. O documento reforça que desta forma Cristo se faz presente e atuante com a comunidade (Mt 18,20) e os leigos, de maneira própria, fazem com que a "Igreja aconteça" (Med 10,12); e, com ela, o Reino vai acontecendo, o testemunho vai sendo produzido e questões urgentes que tocam a vida concreta das pessoas passam a ser tratadas no interior destas comunidades e, desta forma, o compromisso libertador e humanizador se faz presente e é eficaz. A Igreja não é mais um lugar aonde apenas se vai e se ritualiza questões de fé, mas é parte da vida das pessoas, constituindo um novo modo de ir e vir, um lugar, onde além do testemunho, oferece-se um espaço para que possam exercer o profetismo e, através 
dele, um novo modo de reger, de organizar a comunidade e a sociedade. Em outras palavras, nestas comunidades se manifesta o sacerdócio comum, o profetismo e a capacidade de reger, características essenciais do Povo de Deus. Essas comunidades são autênticas, pois acima de tudo são comunidades de fé.

Indo além deste dado, podemos dizer que fazer a Igreja acontecer é agir no mundo pautado por valores do Reino e firme no seguimento do homem de Nazaré. Uma vez que Medellín insiste na ação dos leigos no mundo e que esta ação deve ou pode se fazer também organizada por movimentos, institutos e outras formas de reunião, estas ações também se constituem como ações de Igreja e são capazes de levar ao mundo a causa do Reino. Isso já estava previsto no Decreto Apostolicam actuositatem do Vaticano II e, a partir de agora, esta ação é marcada por uma autonomia e responsabilidades que são próprias, o que vai exigir dos leigos uma busca de maturidade e de conhecimento da causa que buscam e representam.

No entanto, a Igreja só acontece nos lugares em que o Reino é anunciado, e este Reino se faz presente na promoção do amor, da justiça e da paz.

\subsection{Uma espiritualidade própria}

A exigência de uma nova postura para os leigos a partir do Vaticano II e nas especificidades de Medellín também vai projetar um chamado para uma espiritualidade própria. Não apenas como algo que alimente o interior de cada crente, mas como um modo de viver e realizar-se no plano de Deus. Entregar-se a Deus, entregando-se as pessoas, diz Medellín (Med 10,17). Mas o que isso significa realmente? Basicamente, quer-se dizer que uma espiritualidade genuinamente cristã e apropriada à vocação laical (mas não somente para eles!) deve ser uma espiritualidade encarnada, que leve a fazer experiência do concreto da história e do natural da revelação de Deus, neste mundo e neste tempo. O Deus que chama e envia à missão não nos coloca para fora da história, mas dentro dela, junto a ela e para ela. Deste modo, é importante vivenciar a experiência de Deus no cotidiano, buscando um novo modo de sentir e de se manifestar a fé, também em lugares e 
ações tidas como profanas e estranhas a esta realidade. Não existem fórmulas prontas e não se pode ter atitudes exclusivas e/ou excludentes, mas sim atitudes em vistas do compromisso humanizador e libertador, autênticas no Evangelho e provocativas, apropriadas para os desafios de nossa sociedade.

\section{Medellín e sua proposta para os leigos, 50 anos depois...}

Passados 50 anos da conclusão da Conferência de Medellín e do resultado de seu documento, é sempre bom perguntar sobre a atualidade de sua proposta, bem como a relevância e a pertinência de suas interrogações e inquietações. Quando se celebrou 30 anos de Medellín, Gustavo Gutiérrez questionou sobre a sua atualidade, e ele respondeu que sim, que ela se fazia atual por ter aberto caminho e pela ousadia que teve, ao recepcionar de modo criativo o Vaticano II, fazendo opções próprias e marcando um novo tempo para a Igreja e para a sociedade do continente latino-americano, tendo suas perspectivas absorvidas depois em outros ambientes e realidades (GUTIÉRREZ, 1998, p. 237-252). Medellín marcou um novo tempo e deu espaço para uma nova forma de se fazer Igreja e de se fazer teologia, tendo nos pobres e nos últimos uma opção concreta; e isso avança para a radicalidade do Evangelho e para a inculturação que se faz tão necessária em nosso tempo.

Também quando se celebrou os 40 anos de Medellín (42 para ser mais exato) e em vista de um diálogo com a Conferência de Aparecida, Ana Maria Tepedino também se perguntou sobre a atualidade da Conferência (TEPEDINO, 2010, p. 376), e respondeu que Medellín se fazia atual por ter espaço e abertura para novas urgências que vão surgindo e exigem uma ação pontual da Igreja, no caso específico dela [de Ana Maria], na questão de gênero e da mulher (TEPEDINO, 2010, 383). Insiste que Medellín é um “projeto de Igreja” que abre novos caminhos e afeta as gerações seguintes (TEPEDINO, 2010, p. 377). E o mesmo se pode dizer de outros autores e interrogações. Podemos dizer também que esta Conferência dá um tom ao que se constrói depois com Puebla, Santo Domingo e Aparecida, mesmo tendo cada Conferência um ambiente social e 
eclesiológico distinto, somando-se a isso as tensões teológicas e de estruturas que persistem na Igreja pós-Conciliar e que barram alguns avanços mais significativos.

Mas, em relação aos leigos, será que poderemos dizer que Medellín é ainda atual em sua proposta? Mais uma vez temos que dizer sim e a esta resposta se somam algumas razões:

1) O documento de Medellín recepciona o Vaticano II em sua concepção eclesiológica e se propõe em rever a dimensão apostólica dos leigos e sua atuação neste continente (Med 10,1). Todavia, 50 anos depois do Vaticano II e de Medellín temos que dizer que esta é ainda uma realidade a ser buscada e melhor estruturada. Não se questiona aqui a quantidade de leigos envolvidos em ações e projetos eclesiais, eles até são muitos; porém, estes mesmos não estão na sua maioria imbuídos das riquezas que se definiu no Concílio e em Medellín, e ainda se tem muitos deles - em situações de passividade e/ou sem total conhecimento de sua vocação e missão. Que fazem os leigos? Quando fazem? O que falam os leigos? Quando falam? Onde estão os leigos? Quando estão e aonde deveriam estar?... E por aí se vai... Depois de 50 anos, deveríamos estar voltados a outras urgências que reclamam mais a ação pública dos leigos, ao invés disso, ainda mantemos a estrutura pré-conciliar de clérigos de um lado e leigos de outro, hierarquia acima e leigos abaixo, passividade de leigos e clericalismo cada vez mais forte e determinador das questões de fé. Eis um grande problema.

2) 50 anos depois, os leigos ainda insistem em conquistar um espaço eclesial interno, que por certo lhes é de direito; contudo, o grande foco de sua ação deveria ser fora, no mundo, na sociedade, no trabalho, nos grandes problemas e tramas sociais que se fazem urgentes. Medellín insistiu muito na atuação dos leigos na vida pública, no exercício do seu testemunho, na participação em esferas de decisão, no antecipar do Reino em ações concretas, mas o que mais vemos atualmente é o enquadrar dos leigos em situações de dominação, meramente litúrgicas ou paroquiais, onde o frequentar e o estar na Igreja são vistos como "boas ações cristãs", mas que se recorta disso o profetismo, o engajamento, o agir do mundo e o 
transformar de estruturas injustas que fazem do mundo um espaço de pecado social, de injustiça e de pouca solidariedade humana. Pessoas que pensam de modo diferente são afastadas ou se afastam, até mesmo para se manterem fiéis à causa que acreditam e que experimentam na fé, e fazem isso por coerência evangélica e por não aceitarem a dominação. O Vaticano II quis romper com esta estrutura piramidal, ao definir a Igreja como Povo de Deus (COMBLIN, 2002, p. 40), mas o que se percebeu no passar dos anos foi a insistência nesta forma de governar e manter a Igreja, inibindo os leigos naquilo que poderiam contribuir, a seu modo, na construção do Reino. Este é um grave problema que tem a sua base no clericalismo, que nas palavras de Francisco constitui uma enfermidade (FRANCISCO, 2013, n. 102).

3) 50 anos depois de Medellín e já passados 50 anos do Vaticano II temos em Roma um Papa latino-americano, marcado pela teologia deste continente (SCANNONE, 2017) e pela trajetória de suas Conferências Gerais [do CELAM], e que, insistentemente, clama por uma "Igreja em saída” (FRANCISCO, 2013, n. 24). A própria expressão já nos induz a duas questões: que Igreja deve sair [?] e de que modo deve ser esta saída [?]. De modo mais teológico, perguntamos: por quem saímos? Para que saímos? E para onde?... Para Francisco é necessário reformar as estruturas e colocar Cristo no centro, deixando que o Evangelho renove as formas e se adapte aos novos tempos, cujos sinais nos exigem novas posturas, livres de amarras e moralismos doutrinários, que, às vezes, parecem vazios de vida e de fé. A Igreja, da forma como está, não sai, pois ela é conservadora em atitudes e busca a autorreferencialidade; e a saída deve ser em vista de uma boa notícia na história, na alegria do Evangelho, sinal de um Cristo ressuscitado que faz tudo novo e nos abre novas perspectivas de vida, justiça e misericórdia. É onde a atuação dos leigos se faz urgente e necessária. Em uma carta destinada ao Cardeal Marc Ouellet, Francisco reclama que "a hora dos leigos", tão aguardada durante o Concílio "está tardando a chegar" (FRANCISCO, 2016), e, mesmo tendo os leigos certa culpabilidade, Francisco acusa ali a estrutura eclesial, o clericalismo, que não permite que os leigos assumam a sua vocação e missão e despertem para uma 
maturidade de fé. Perguntamos, então: será que o chamado de Francisco e, sendo ele um latino-americano, não reporta aos leigos e à Igreja deste continente uma nova postura e um novo empreendimento a partir e com os leigos, em vista de uma saída pelo Reino, em prol da justiça, da promoção dos pobres e excluídos e de uma responsabilidade pública e política pelo continente? O contexto sócio-político e econômico de hoje não é o mesmo da época da Conferência de Medellín, todavia é tão desafiador quanto aquele, e isso exige uma ação efetiva dos leigos na vida pública. Esta seria uma Igreja em saída!

Estes são apenas alguns itens que destacamos para dizer apenas que a atualidade da proposta de Medellín para os leigos é ainda urgente e atual. Medellín é um caminho obrigatório. É necessário percorrê-lo e é importante deixar-se tocar pela sua novidade, criatividade, liberdade e ousadia. Voltar-se a esta Conferência é buscar uma memória subversiva e profética, tão necessária quanto incômoda; e é incômoda (para alguns) porque ainda é necessária.

\section{Conclusão}

O que se pretendeu nestas breves palavras foi fazer um resgate e uma memória da questão dos leigos abordada na Conferência de Medellín, naquilo que foi específico em suas conclusões e daquilo que precisamos ainda olhar e acolher com mais profundidade. Entendemos que celebrar 50 anos desta Conferência é fazer reviver um sentimento profético que mudou e marcou a trajetória da Igreja deste continente. É, também, reviver compromissos e repensar estruturas. É buscar na história chaves de interpretação para o nosso tempo, aprendendo e atualizando o chamado vocacional diante das novas perguntas que nos chegam e nos interpelam a fé. Medellín foi um marco. A situação da Igreja em nosso continente ainda é uma realidade que necessita ser enfrentada. O papel dos leigos e a sua missão ainda não foram assumidos totalmente e merecem especial atenção, ainda mais quando junto aos 50 anos de Medellín, no Brasil, se celebra o Ano do Laicato. Que isso seja um ponto de reflexão para uma saída profética e inspirada nos valores do Reino.

Horizonte, Belo Horizonte, v. 16, n. 50, p. 632-647, maio/ago. 2018 - ISSN 2175-5841 


\section{REFERÊNCIAS}

CELAM. Conclusões da Conferência de Medellín, 1968 - Trinta anos depois, Medellín é ainda atual? São Paulo: Paulinas, 1998.

COMBLIN, José. O povo de Deus. São Paulo: Paulus, 2002.

COMPÊNDIO do Vaticano II. Constituições, decretos, declarações. Petrópolis; RJ: Vozes, 1968.

FORTE, Bruno. A Igreja: ícone da Trindade. São Paulo: Loyola, 2005.

FRANCISCO. Carta do Santo Padre ao Cardeal Marc Ouellet, Presidente da Pontifícia Comissão Para a América Latina. Disponível em:<https://w2.vatican.va/content/francesco/pt/letters/2016/documents/papafrancesco_20160319_pont-comm-america-latina.html>. Acesso em: 31 dez. 2017.

FRANCISCO. Evangelii gaudium. São Paulo: Loyola, 2013.

GUTIÉRREZ, Gustavo. A atualidade de Medellín. In: CELAM. Conclusões da Conferência de Medellín, 1968 - Trinta anos depois, Medellín é ainda atual? São Paulo: Paulinas, 1998, p. 237-252.

SCANNONE. Juan Carlos. La teología del pueblo. Raíces teológicas del Papa Francisco. Maliaño: Sal Terrae, 2017.

SCATENA, Silvia. In populo pauperum. La chiesa latino-americana dal Concilio a Medellín (1962-1968). Bologna: Il Mulino, 2008.

TEPEDINO, Ana Maria. De Medellín a Aparecida: marcos, trajetórias e perspectivas da Igreja Latino-americana. Atualidade Teológica, n. 36, p. 376-394, 2010. 